2 Reynolds JEF. Methotrexate. In: Reynolds JEF ed. Martindale - The extra pharmacopoeia, London: Royal Pharmace

3 Tracy TS, Worster T. Bradley JD, Greena PK, Brater DC. Methotrexate disposition following concomitant administration of ketoprofen piroxicam and flurbiprofen in patients with rheumatoid arthritis. Br f Clin Pharmacol 1994, 37:453-6.

4 Mason P. Fish oils. In: Mason P, ed. Handbook of dietary supplements, Oxford: Blackwell Science Ltd, 1995; pp 73-8.

5 Harvey SC, Withrow CD. Cardiovascular drugs. In: Gennaro AR, ed. Remington's Phardrugs. In: Gennaro AR, ed. Remington's Pharing Company, 1990; pp 858-9.

\section{Thyrotoxicosis and antithyroid drugs}

\section{Sir,}

In their recent self-assessment case on thyrotoxicosis and antithyroid drugs, Monakier and Shilo' ${ }^{1}$ stated in the learning box that once agranulocytosis is diagnosed, antithyroid drugs should be stopped and treatment with granulocyte colony-stimulating factors (GCSFs) initiated, in addition to isolation and antibiotic administration. They did not mention the importance of the duration of the neutropenia in deciding to starting therapy with G-CSF. In 1996 a panel convened by the American Society of Clinical Oncology concluded that G-CSF or GM-CSF is unnecessary in patients with neutropenia of short duration (less than a week), but that it may benefit patients with prolonged neutropenia. ${ }^{2}$ Thus, it was probably unnecessary to treat their patient with G-CSF.

MOHAMMED R MAJEED Department of Molecular Medicine, University of Auckland, Private Bag 92019, Auckland, New Zealand

Accepted 19 November 1997

1 Monakier D, Shilo S. Thyrotoxicosis and antithyroid drugs. Postgrad Med $\mathcal{f}$ 1997;73:335-

2 American Society of Clinical Oncology. Update of recommendations for the use of hematopoiof recommendations for the use of hematopoi-
etic colony-stimulating factors: evidence based etic colony-stimulating factors: evidence based
clinical practice guidelines. $\mathcal{F}$ Clin Oncol 1996; clinical practice

This letter was forwarded to the authors who responded as follows:

Sir,

The American Society of Clinical Oncology paper you mention deals with the use of haematopoietic CSF following chemotherapy and does not deal with other drug-induced neutropenia. It states: “... Existing clinical data suggest that starting G-CSF or GMCSF between 24 and 72 hours subsequent to chemotherapy may provide optimal neutrophil recovery". (p 1959, para 10). The recommendation is to start CSF even before the appearance of agranulocytosis. Our recommendation, in a case of agranulocytosisis induced by antithyroid medications, is to start CSF when agranulocyctosis appears, in order to try and avoid fever and infections and to reduce infection complications.

S SHILO

Endocrine Service, Shaare Zedek Medical Centre, ferusalem, PO Box 3235, ferusalem, Israel 91035

\section{Sarcoidosis-lymphoma syndrome in a woman with acromegaly}

Sir

We read the article by Romero et al on sarcoidosis-lymphoma syndrome ${ }^{1}$ with great interest. We would like to report a case of a woman with acromegaly in whom nonHodgkin's lymphoma was diagnosed 6 years after sarcoidosis.

In 1979, a 38-year-old woman was admitted with complaints of irregular fever and cervical lymphadenopathy. She had a history of active acromegaly which had been treated by local pituitary ${ }^{60} \mathrm{Co}$ irradiation (3340 cGy in 20 fractions) two years earlier. At presentation she was in a good clinical condition. Physical examination revealed bilateral, movable cervical and supraclavicular enlarged lymph nodes without hepatosplenomegaly. Chest X-ray was normal. Lymphography showed retroperitoneal and bilateral inguinal lymphadenopathy. Full blood counts were normal; the erythrocyte sedimentation rate was $35 \mathrm{~mm} / \mathrm{h}$. After histological examination of two cervical lymph nodes, a diagnosis of sarcoidosis was established. She was put on $45 \mathrm{mg}$ of prednisolone daily. After symptoms subsided, steroid therapy was continued for one year.

She remained asymptomatic for a follow-up period of 5 years. In 1986 she was again admitted to hospital with fever, weight loss, goitre and cervical lymphadenopathy. Her symptoms did not subside on 6 months ambulatory treatment with steroids. Other clinical examination findings were hilar enlargement, revealed on chest X-ray, and lymphatic infiltration of bone marrow (up to $20 \%$ ). Histological examination of the cervical node demonstrated centroblastic lymphoma. The patient received six courses of CVP chemotherapy (cyclophosphamide, vincristin and prednisolone). A reduction of symptoms, including a reduction of the enlarged lymph nodes and goitre, were noted. The patient remains asymptomatic.

Brincker, in his description of so-called sarcoidosis-lymphoma syndrome ${ }^{2}$ pointed to three typical features: sarcoidosis preceeds lymphoma by several years, the patients are on average 10 years older than other patients with sarcoidosis, and an association with Hodgkin's lymphoma is more frequent. Our patient met two of these three criteria. She was in her forties when she developed sarcoidosis. She had received steroid treatment and developed lymphoma 6 years after the diagnosis of sarcoidosis.

The immunologic abnormalities in our patient could have been initiated by radiotherapy. This might have provoked the development of sarcoidosis. Consequently an increased mitotic activity and dysregulation of lymphocytes observed in sarcoidosis, ${ }^{34}$ as well as steroid therapy, contributed to the development of lymphoma. We believe that our case supports the theory of non-random association between sarcoidosis and lymphoma and the existence of sarcoidosis-lymphoma syndrome.

M SIEKIERSKA-HELLMANN K SWORCZAK

Division of Endocrinology

$3^{\text {rd }}$ Department of Internal Medicine,

Medical University of Gdañsk, Poland

Accepted 21 January 1998

1 Romero J, Ramon y Cajal S, Vargas JA, et al. Association of sarcoidosis, low-grade B-lymphoma and epidermoid carcinoma. Postgrad Med f 1997;73:580-4.

2 Brincker H. The sarcoidosis-lymphoma synBrincker $H$. The sarcoidosis-lymph
drome. Br $f$ Cancer 1986;54:467-73.

3 Danielle RP, Dauber JH, Rossmann MD. Danielle RP, Dauber JH, Rossmann $\mathrm{MD}$.
Immunologic abnormalities in sarcoidosis. Ann Intern Med 1980;92:406-11.

4 Linnenberg HS, Medici TC, Rhynet K. Das 'Sarkoidosis-Lymphoma-Syndrom'-Eine Lymphozyten Fehlregulation? Pneumonologie 1992;46:229-35.

\section{Understanding scientific papers}

Sir

We would like to offer an addendum to the articles published in recent years in various journals ${ }^{12}$ on how to read medical literature. This addendum, a translation of some of the phrases commonly used in scientific and clinical articles, has been gleaned from various sources and we have made some modifications of our own. We hope that readers will find it both instructive and amusing.

- It has long been known that... = We haven't bothered to look up the relevant literature or the original reference.

- While it has not been possible to provide definite answers to these questions... = The experiment did not work out, but we figured we could at least get a publication out of it.

- Typical results are shown... = Only the positive results are shown.

- It is suggested/believed... = We think.

- It is generally suggested/believed... = A couple of other guys think so too.

- It is clear that much additional work will be required before a complete analysis of the results... = We don't understand what happened.

- Unfortunately, a quantitative theory to account for the results has not yet been formulated... $=$ No one else understands it either.

- Correct within an order of magnitude = Wrong.

- It is clear... = It is not clear.

- It is obvious... = We think that is the way it should be, but we cannot explain why.

RAZ GROSS

The Chaim Sheba Medical Center, Tel Hashomer, Israel ALAN DEROWE

Meir Hospital, Sapir Medical Center, Kfar Sava, Israel

Correspondence to Raz Gross, MD, 36 King David Blvd, Tel Aviv 64237, Israel

Accepted 19 November 1997

1 Greenhalgh T. How to read a paper: Getting your bearings (deciding what the paper is about). BMF 1997;315:243-6.

2 Guyatt GH, Rennie D. User's guides to the medical literature. $\mathcal{F A M A}$ 1993;270:2096-7. 